\title{
1 Extracellular Electron Transfer by Shewanella oneidensis Controls Pd Nanoparticle 2 Phenotype
}

3 Christopher M. Dundas ${ }^{1}$, Austin J. Graham ${ }^{1}$, Dwight K. Romanovicz ${ }^{2}$, Benjamin K. Keitz ${ }^{1 *}$

$4{ }^{1}$ McKetta Department of Chemical Engineering, University of Texas at Austin, Austin, TX 578712 ;

$6 \quad{ }^{2}$ Institute for Cellular and Molecular Biology, University of Texas at Austin, Austin, TX 78712;

$7 \quad$ *To whom correspondence should be addressed. Email: keitz@utexas.edu

\section{Abstract}

Biological production of inorganic materials is impeded by relatively few organisms possessing genetic and metabolic linkage to material properties. The physiology of electroactive bacteria is intimately tied to inorganic transformations, which makes genetically tractable and well-studied electrogens, such as Shewanella oneidensis, attractive hosts for material synthesis. Notably, this species is capable of reducing a variety of transition-metal ions into functional nanoparticles, but exact mechanisms of nanoparticle biosynthesis remain ill-defined. We report two key factors of extracellular electron transfer by $S$. oneidensis, the outer membrane cytochrome, MtrC, and soluble redox shuttles (flavins), that affect $\mathrm{Pd}$ nanoparticle formation. Changes in the expression and availability of these electron transfer components drastically modulated particle phenotype, including particle synthesis rate, structure, and cellular localization. These relationships may serve as the basis for biologically tailoring Pd nanoparticle catalysts and could potentially be used to direct the biogenesis of other metal nanomaterials.

\section{Introduction}

24 Control over cellular machinery has enabled the production of diverse compounds including 25 pharmaceuticals, fuels, fine chemicals, and soft materials ${ }^{1-3}$. However, microbial engineering of 26 metal and metal oxide products remains a significant challenge. Attributes such as electron 27 transfer and nucleation are typically absent from organic biosyntheses, and their presence adds 28 increased complexity to inorganic transformations. As a result, the enzymatic and metabolic 29 factors that drive material formation in biological systems have been challenging to study and 30 manipulate ${ }^{4}$. Despite the paucity of bioengineered inorganic products, microbial transformation of 31 inorganics occurs quite frequently in nature. Several organisms generate highly functional and 32 ordered materials, including metal nanoparticles, silicas, calcium carbonates, and metal oxides ${ }^{5-}$

337 . In these systems, coordinated protein and metabolite networks exert control over material 34 morphology, composition, and function. For instance, the magnetotactic bacterium, 
Magnetospirillum gryphiswaldense, uses several proteins that govern nucleation, electron transfer, and vesicle formation to generate size-controlled magnetite nanoparticles ${ }^{8}$. This example highlights the capability of living systems to tailor inorganic structure-function relationships and suggests that exploiting naturally-occurring pathways may provide a means for designer material biosynthesis.

Electroactive bacteria are attractive hosts for inorganic materials engineering, as a diversity of soluble and insoluble inorganic substrates can be incorporated into their metabolism ${ }^{9}$. Whereas magnetotactic bacteria are limited to generating iron oxides, electrogens can transfer respiratory electron flux onto several metal species, including $\mathrm{Cu}(\mathrm{II}), \mathrm{U}(\mathrm{VI}), \mathrm{Ag}(\mathrm{I}), \mathrm{Au}(\mathrm{III})$, and $\mathrm{Pd}(\mathrm{II})$, to generate functional nanoparticles ${ }^{5}$. These particles have found catalytic utility in bioremediation and organic synthesis, and in some cases exhibit superior activity to those synthesized via traditional methods. However, it is generally unclear how electroactive physiology dictates the structural and functional properties of produced nanoparticles.

One electroactive bacterium, Shewanella oneidensis MR-1, is poised to address this issue, as it directs metabolic electron flux onto metals using a well-characterized electron transport pathway ${ }^{10}$. The organism's genetic tractability has also facilitated understanding and control of

51 this network, with knockout, complementation, and overexpression studies leading to

52 identification of important redox-active metalloproteins and small-molecules ${ }^{11}$. Notably, this

53 pathway can reduce substrates located outside the bacterial outer membrane in a process known

54 as extracellular electron transfer (EET). Despite significant progress in applying this system 55 towards bioremediation and microbial fuel cell engineering, elucidating the function of EET

56 components in nanoparticle formation has proven challenging. Whereas the outer membrane 57 cytochromes, MtrC and OmcA, are primary mediators of EET to iron oxides and electrodes ${ }^{12,13}$, 58 their activity in nanoparticle formation appears largely dependent on culture conditions and the 59 identity of metal reduced. For example, a knockout strain deficient in these proteins changed the cellular localization of produced $\mathrm{UO}_{2}$ nanoparticles relative to those of $\mathrm{MR}-1^{14}$, but had no measured effect on the kinetics of Pd or Cu nanoparticle formation ${ }^{15,16}$. Additional proteins have

62 been identified as influencing nanoparticle formation rates, including hydrogenases and other 63 periplasmic reductases ${ }^{17,18}$, but little is known of their influence on particle properties. 64 Furthermore, the importance of soluble redox shuttles (flavins) in EET by Shewanella has become 65 increasingly apparent ${ }^{19}$, but their impact on nanoparticle synthesis is wholly unexamined.

66 To better inform the design of material syntheses using S. oneidensis, we explored the role of 67 key EET factors in the formation of Pd nanoparticles. Pd was chosen as it is one of the more well68 studied nanoparticles generated by $S$. oneidensis and enabled us to draw comparisons with 
previous reports ${ }^{15,20-22}$. Pd nanoparticles are also industrially-relevant catalysts whose catalytic activity is largely dictated by their crystallographic structure and morphology ${ }^{23}$. Bio-based stabilization of specific $\mathrm{Pd}$ crystal facets was previously demonstrated via peptide-directed synthesis $^{24}$, and we reasoned that $S$. oneidensis cells may exhibit similar control of particle nucleation and growth. In contrast to previous works, the EET machinery of S. oneidensis also affords the opportunity to genetically and metabolically instruct electron transfer to $\mathrm{Pd}(\mathrm{II})$ ions during nanoparticle synthesis. Thus, we tested the effect of $S$. oneidensis genotype and the role of redox-active small molecules in $\mathrm{Pd}$ nanoparticle formation. Here, we report two factors of $S$. oneidensis electron transport that strongly influence nanoparticle phenotype: the outer membrane cytochrome, MtrC, and soluble redox shuttles (flavins). After manipulating the bacterial concentration of these species, through control of gene expression and exogenous

80 supplementation, respectively, we observed drastic effects on the synthesis rate, size, and cellular 81 localization of biogenic nanoparticles. Identification of these factors provides proof-of-principle for 82 using genetic and metabolic manipulation to tune the properties of $\mathrm{Pd}$ and potentially other metal nanoparticles generated by $S$. oneidensis.

Results and Discussion

\section{Optimizing S. oneidensis Control Over Nanoparticle Biosynthesis}

87 To drive S. oneidensis control over Pd nanoparticle formation, we first identified nanoparticle 88 synthesis conditions that minimized abiotic effects and exhibited unambiguous nanoparticle 89 phenotypes. Specifically, we examined how reaction media formulation and method of anoxic 90 culture influenced nanoparticles formed by $S$. oneidensis MR-1. The general procedure for Pd 91 nanoparticle biosynthesis was as follows: MR-1 was anaerobically pregrown overnight to 92 stationary-phase in Shewanella Basal Medium (SBM) containing lactate/fumarate, anaerobically 93 washed with degassed SBM, and finally used to inoculate a Pd nanoparticle reaction mixture (final $94 \mathrm{OD}_{600} \sim 0.2$ ). Whole mount transmission electron microscopy (TEM) enabled initial assessment of 95 different conditions, as the bacteria became palladized upon exposure to $\mathrm{Pd}(\mathrm{II})$ and adherent 96 nanoparticles could be visualized by electron micrographs.

97 Choice of electron donor can greatly affect bacterial nanoparticle formation, as many 98 metabolically accessible electron donors (e.g. formate, hydrogen) also abiotically reduce 99 palladium ions ${ }^{25}$. Indeed, we found that the hydrogenous atmosphere (3\%) of a humidified 100 anaerobic glovebox caused autocatalytic reduction of palladium in the absence of bacteria. Thus, 101 we used butyl rubber-stoppered Hungate Tubes purged with argon to maintain anaerobicity for 102 bacterial pregrowth and nanoparticle biosynthesis reactions. As lactate is relatively inert to 
103 palladium and generates metabolic electron flux in Shewanella, we used it as our primary electron

104 donor. Reaction mixtures omitting lactate or any other electron donor showed no Pd(II) reduction

105 (Figure S1). We also assessed the influence of culture medium components that could cause 106 abiotic reduction of $\mathrm{Pd}(\mathrm{II})$. Prior to bacterial inoculation of the reaction mixture, S. oneidensis was

107 pregrown in SBM supplemented with casamino acids. When the nanoparticle reaction mixture 108 was similarly supplemented, small Pd nanoparticles were formed on bacteria (<10 nm) (Figure 109 S2). In contrast, mixtures omitting casamino acids had a larger nanoparticle size distribution, with 110 particles generally falling within one of two populations: small $(<10 \mathrm{~nm})$ and large $(\sim 50 \mathrm{~nm})$ 111 particles. We speculated that the presence of free cysteines may cause abiotic reduction of $\operatorname{Pd}(\mathrm{II})$ 112 and lead to fewer large particles formed on bacteria. Thus, to minimize abiotic effects we utilized 113 reaction mixtures that lacked casamino acids.

114 The intracellular space is a reducing environment and leakage of promiscuous reductants (e.g. $115 \mathrm{NADH}$, glutathione) through compromised membranes could also contribute to $\mathrm{Pd}(\mathrm{II})$ reduction. 116 To address this, we performed viability measurements to quantify the effect of increasing 117 concentration of $\mathrm{Pd}(\mathrm{II})$ in the $\mathrm{S}$. oneidensis reaction mixtures. Viability was quantified using the

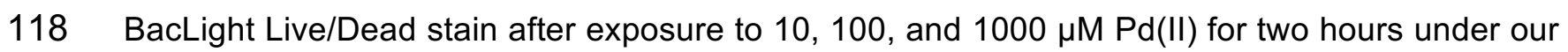
119 standard nanoparticle synthesis conditions. S. oneidensis viability exhibited a dose-dependent 120 response for the concentration range tested, varying from $\sim 80 \%$ to $\sim 30 \%$ viable with increasing $121 \mathrm{Pd}(\mathrm{II})$ concentration (Figure S3). To mitigate the effects of promiscuous reducing agents and cell 122 death, but also balance sufficient nanoparticle yield for characterization and analysis, we chose $123100 \mu \mathrm{M} \mathrm{Pd}(\mathrm{II})$ as our primary concentration for nanoparticle synthesis reactions (except where 124 noted).

Loss of Outer Membrane Cytochromes Decreases Pd Nanoparticle Size and Alters Cellular Localization

Pathways for both soluble and insoluble metal reduction are well-studied in S. oneidensis ${ }^{10}$. These EET pathways utilize a network of electron transfer proteins to direct metabolic electron flux from the cytoplasm, across the periplasm, and into the extracellular space (Figure 1a). As reduction of $\mathrm{Pd}(\mathrm{II})$ is necessary for nanoparticle formation, we examined the particle phenotypes of strains lacking key components of this network. The outer membrane $c$-type cytochromes, MtrC 134 shown some influence on affecting the localization of produced nanoparticles ${ }^{14}$. We hypothesized 135 that they may also participate in $\mathrm{Pd}(\mathrm{II})$ reduction and that a knockout strain $(\Delta m \operatorname{tr} \Delta \mathrm{OmcA})$ would 136 exhibit distinct nanoparticle properties. Additionally, periplasmic hydrogenases have 
137 demonstrated $\mathrm{Pd}(\mathrm{II})$ reduction activity in S. oneidensis and several other bacteria ${ }^{15,26,27}$. Thus, we 138 also examined the characteristics of Pd nanoparticles formed by a hydrogenase deficient strain 139 (

140 Noticeable differences between nanoparticle reaction mixtures containing different strains 141 were observed shortly after bacterial inoculation. Reactions inoculated with MR-1 or the $142 \Delta h y d A \Delta h y a B$ strain turned a diffuse black color that is characteristic of reduced $\mathrm{Pd}^{27}$, while those 143 with the $\triangle m \operatorname{tr} C \Delta o m c A$ mutant remained relatively colorless. Similarly, the cell pellets for the MR-

1441 and the $\triangle h y d A \Delta h y a B$ strains were dark black, while the $\Delta m t r C \Delta o m c A$ pellet appeared light grey 145 (Figure S4). Whole mount TEM showed that these differences arose based on the types of 146 nanoparticles generated by each strain. The large particle population observed on MR-1 was not 147 found on the $\Delta m t r C \Delta o m c A$ strain and only small nanoparticles were adherent to this cytochrome 148 double knockout (Figure S5). In contrast, nanoparticles on the $\triangle h y d A \Delta h y a B$ strain were identical 149 to those on MR-1, exhibiting both large and small particle populations. As whole mount TEM 150 cannot resolve the cellular location of particles, thin section TEM was performed. Thin sectioning 151 of all three strains revealed that the two populations of particles not only differ in size, but also in 152 cellular localization: smaller $(<10 \mathrm{~nm})$ particles localized to the periplasm and larger particle 153 aggregates $(\sim 50 \mathrm{~nm})$ adhered to the outer membrane and faced the extracellular space. 154 Consistent with whole mount observations, MR-1 and the $\triangle h y d A \Delta h y a B$ strain contained both 155 particle populations, while the $\triangle m t r C \Delta o m c A$ strain lacked extracellular particles (Figure 1b-g, S6). 156 A similar change in $\mathrm{UO}_{2}$ nanoparticle localization has previously been observed with this mutant ${ }^{14}$. 157 Across all strains, no Pd particles were detected within the bacterial cytoplasm, indicating that 158 reduction primarily occurred in the periplasm or extracellular space. Comparisons between 159 bacteria palladized at 100 and $1000 \mu \mathrm{M} \mathrm{Pd}$ (II) showed that more particles were produced per cell 160 at higher $\mathrm{Pd}(\mathrm{II})$ concentrations. However, nanoparticle localization was more binary at the lower $161 \mathrm{Pd}(\mathrm{II})$ concentration. At low $\mathrm{Pd}(\mathrm{II})$ concentrations, particles exclusively nucleated extracellularly 162 on the outer membrane (MR-1, $\Delta h y d A \Delta h y a B)$ or within the periplasm $(\Delta m t r C \Delta o m c A)$. Together, 163 our data suggests that low $\mathrm{Pd}(\mathrm{II})$ concentrations accentuate genotypic differences, whereas 164 decreased cell viability at high $\mathrm{Pd}(\mathrm{II})$ concentrations (Figure S3) results in more promiscuous $165 \mathrm{Pd}(\mathrm{II})$ reduction.

166 In addition to TEM, powder x-ray diffraction (PXRD) was used to characterize the properties 167 of bacterial Pd nanoparticles. PXRD patterns can reveal the chemical identity and relative size of 168 analyzed nanomaterials. Differences between S. oneidensis strains were detected by PXRD, and 169 corroborated trends observed by TEM (Figure S7). While nanoparticles formed by MR-1 and the $170 \Delta h y d A$ $\Delta$ yaB mutant had comparable patterns, broader peaks were observed for those from the 
$171 \Delta m \operatorname{tr} \Delta$ omcA strain, indicating smaller grain size of $\mathrm{Pd}$ nanocrystallites as predicted by the

172 Scherrer equation ${ }^{28}$. The observed peak locations were consistent with previous Pd-Shewanella

173 studies and with abiotic $\operatorname{Pd}(0)$ patterns $^{20}$, verifying that peaks were a result of palladization. These

174 results further demonstrate the importance of outer membrane cytochromes in controlling 175 nanoparticle properties and show that PXRD can be used to distinguish genotypic differences.

176 The existence of the two particle populations illuminates how bacterial membranes and outer 177 membrane cytochromes influence nanoparticle nucleation and growth. Cellular 178 compartmentalization appears to physically constrain nanoparticle structure, as evidenced by 179 intracellular particles limited in size by periplasmic dimensions (<50 nm), while extracellular 180 particles further aggregated $(>50 \mathrm{~nm})$. Importantly, bacterial genotype controlled particle 181 localization, since loss of outer membrane cytochromes MtrC and OmcA was coincident with loss 182 of outer membrane particles (Figure 1c, 1f). Nanoparticle reaction mixtures that replaced $S$. 183 oneidensis with a cytochrome-lacking bacterium, Escherichia coli MG1655, similarly had no large 184 extracellular particles formed on the bacteria (Figure S8). Additionally, post-palladization viability 185 studies performed on MR-1 and the $\Delta m \operatorname{tr} \Delta$ omcA strain showed that changes in cell viability do 186 not account for the differences between particle phenotypes (Figure S9). Together, this indicates 187 that the outer membrane cytochromes are critical for extracellular Pd nucleation and likely serve 188 as sites for electron transfer to $\mathrm{Pd}(\mathrm{II})$.

\section{Loss of Outer Membrane Cytochromes Attenuates Pd(II) Reduction}

191 Generally, the structures of biosynthesized metabolites are invariant to the rate at which they 192 are produced. In contrast, metal ion reduction rates can exert significant influence over the size 193 and morphology of produced nanoparticles ${ }^{29}$. To assess whether reduction kinetics could explain 194 differences in Pd particle size/localization between S. oneidensis strains, we quantified Pd(II) 195 concentrations over the course of nanoparticle synthesis.

196 With all strains, extracellular $\mathrm{Pd}(\mathrm{II})$ concentrations were measured as $\sim 50 \mu \mathrm{M}$ at the first time197 point (starting concentration was $100 \mu \mathrm{M}$ ), indicating rapid $\mathrm{Pd}(\mathrm{II})$ adsorption to cells upon bacterial 198 inoculation (Figure 2). Reaction mixtures with E. coli MG1655 also showed Pd(II) adsorption to 199 cells, but no $\mathrm{Pd}$ (II) reduction was detected on the same time scale (Figure S10). Following the 200 initial adsorption event, we measured a comparable first-order $\mathrm{Pd}(\mathrm{II})$ reduction rate between MR2011 and the hydrogenase deficient mutant when lactate was utilized as an electron donor (Figure 2, 202 S11). Although kinetic differences between these strains have previously been measured when 203 utilizing formate ${ }^{15}$, less metabolic electron flux is directed to the quinone pool from formate 204 catabolism $^{30}$. This suggests that the outer membrane cytochromes are primarily responsible for 
$205 \mathrm{Pd}(\mathrm{II})$ reduction when electron flux can be directed through the Mtr pathway, which utilizes the 206 quinone pool. Accordingly, the $\triangle m \operatorname{trC} \Delta o m c A$ strain showed significantly attenuated $\operatorname{Pd}(\mathrm{II})$ 207 reduction relative to MR-1. These results differed from a previous study, where a strain lacking 208 these cytochromes had a rate of reduction rate that was identical to MR-1 ${ }^{15}$. We attribute these 209 conflicting observations to the significant effects that buffering capacity can exert on the kinetics 210 of $\mathrm{Pd}(\mathrm{II})$ reduction by $S$. oneidensis. We note that our bacterial pregrowth and nanoparticle 211 reaction mixtures utilized substantially more buffered media (100 mM HEPES) than this previous 212 study (30 mM HEPES). Even under our conditions, Pd(II) reduction rate greatly decreased with 213 increasing age of dissolved HEPES in pregrowth and reaction media (Figure S12). Cell growth 214 can alter culture medium acidity, and the $\mathrm{pH}$ stability of strongly buffered media may counter 215 physiological shifts such as cytochrome downregulation or inactivity that otherwise occurs ${ }^{31}$. 216 Alternatively, the loss of MtrC and OmcA increased the variability between biological replicates, 217 which could arise from the increased role of promiscuous reductants as opposed to specific 218 electron transport pathways. This may have further obscured kinetic differences between strains 219 in previous studies. Taken together, our results are consistent with previously purported 220 nanoparticle formation mechanisms by S. oneidensis: $\mathrm{Pd}(\mathrm{II})$ adsorbs to cells, $\mathrm{Pd}(\mathrm{II})$ is reduced, 221 and Pd nanoparticles nucleate ${ }^{15}$. Notably, our results highlight the importance of outer membrane 222 cytochromes in the latter two steps.

\section{MtrC Expression Controls Extracellular Pd Nanoparticle Formation}

225 To better understand the role of $\mathrm{MtrC}$ and $\mathrm{OmcA}$ in $\mathrm{Pd}(\mathrm{II})$ reduction and nanoparticle formation, we complemented the $\Delta m t r C \Delta o m c A$ strain with one of three plasmids that was either an empty control vector or vectors carrying $m t r C$ and omcA under constitutive control ${ }^{32}$.

We first tested whether the presence of either MtrC or OmcA was sufficient to restore the extracellular particle phenotype observed with MR-1. Whole mount TEM showed that $\triangle m t r C \Delta o m c A$ strains carrying either an empty vector or an omcA-expressing vector were unable to form large nanoparticles that are characteristic of extracellular localization (Figure S13). 232 However, large particles were observed on the double knockout strain complemented with a 233 plasmid carrying $m t r C$. Thin section TEM confirmed that large particles formed by this mtrC234 complemented strain were extracellular and adherent to the bacterial outer membrane (Figure 3, 235 S14). MR-1 carrying an empty plasmid exhibited an identical phenotype, which validated that 236 MtrC expression is responsible for extracellular particle nucleation and plasmid maintenance does 237 not interfere with nanoparticle formation. These results are consistent with previous reports that 238 describe MtrC functioning in the Mtr pathway ${ }^{12}$. In these studies, MtrC expression restored EET 
239 to $\mathrm{Fe}(\mathrm{III})$ species in outer membrane cytochrome deficient strains, while OmcA only partially 240 contributed to EET. OmcA may act as a non-critical helper protein that requires MtrC to receive 241 electrons for subsequent metal reduction. Our results suggest that this mechanism is also true for $242 \mathrm{Pd}(\mathrm{II})$ reduction.

243 We next measured $\mathrm{Pd}(\mathrm{II})$ reduction kinetics with the mtrC-complemented mutant to assess 244 whether wild-type $\mathrm{Pd}(\mathrm{II})$ reduction was rescued. Indeed, reduction was substantially faster with 245 the $m$ trC-complemented mutant relative to the same mutant carrying an empty plasmid (Figure 4, 246 S11). Moreover, the $m t r C$-complemented mutant exhibited a faster $\mathrm{Pd}(\mathrm{II})$ reduction rate compared 247 to MR-1 carrying an empty plasmid. This is likely due to different MtrC expression levels between 248 our engineered strain and MR-1. Taken together with our microscopy and knockout results, our 249 complementation studies confirm that MtrC is a critical enabler of $\mathrm{Pd}(\mathrm{II})$ reduction and extracellular 250 nanoparticle nucleation. The complementation kinetics also suggest that manipulating expression 251 levels of MtrC may be a viable means for tuning $\mathrm{Pd}(\mathrm{II})$ reduction rates or controlling $\mathrm{Pd}$ 252 nanoparticle localization.

253

\section{Flavins Decrease Outer Membrane-Nanoparticle Size}

Flavins are a family of redox-active small-molecules that function in E. coli, Shewanella, and other microorganisms ${ }^{33}$. In Shewanella, they have been implicated in a unique role of accelerating electron transfer to insoluble metal substrates ${ }^{19}$. Strains lacking a key periplasmic flavin exporter $(\Delta b f e)$ exhibit significantly attenuated electron transfer to iron oxides and electrodes ${ }^{34}$. It has been proposed that flavin binding to MtrC and other outer membrane cytochromes is critical for enabling direct-contact electron transfer to insoluble substrates ${ }^{35}$. Furthermore, flavins are known chelators that can bind to a variety of soluble and insoluble metal species ${ }^{19,36}$. These findings suggest that flavin concentration may also play a role in nanoparticle synthesis by influencing electron transfer and/or instructing metal binding.

We measured $\mathrm{Pd}$ nanoparticle properties in response to flavin supplementation of the nanoparticle reaction mixture. Nanoparticle size decreased in a dose-dependent manner with increasing riboflavin concentration $(1,10,100 \mu \mathrm{M})$, when analyzed by whole mount TEM (Figure S15). Similarly, supplementing reaction mixtures with flavin mononucleotide $(100 \mu \mathrm{M})$ caused a small-particle phenotype (Figure S16). Thin section TEM demonstrated that in the presence of exogenous flavins, Pd nanoparticles were localized to both the periplasm and outer membrane. However, extracellular particles were significantly smaller $(<10 \mathrm{~nm})$ and in greater number per cell compared to the non-supplemented reaction mixtures (Figure 5). This differs substantially

272 from strains lacking $m t r C$, which generated smaller particles exclusively confined to the periplasm. 
273 Riboflavin and flavin mononucleotide are thought to directly mediate electron transfer by binding

274 to OmcA and $\mathrm{MtrC}^{35}$, respectively, and an increase in cytochrome-binding may explain the greater

275 number of $\mathrm{Pd}$ nanoparticles on the outer membrane. In contrast to flavins, supplementing other

276 respiration substrates (sodium fumarate and Fe(III)-citrate) showed no effect on nanoparticle size

277 (Figure S17, S18). Additionally, we measured no effect on cell viability when supplementing with

278 flavins, which discounts the influence of stress response on affecting nanoparticle formation

279 (Figure S19). These results support our hypothesis that, unlike other metabolites, flavins play a

280 role in either electron transfer to $\mathrm{Pd}(\mathrm{II})$, particle nucleation/growth, or both.

To further investigate this mechanism, we measured $\mathrm{Pd}(\mathrm{II})$ reduction kinetics in the presence 282 of $100 \mu \mathrm{M}$ of exogenous riboflavin or flavin mononucleotide. $\mathrm{Pd}(\mathrm{II})$ reduction rates of MR-1 283 supplemented with riboflavin were slightly, yet significantly, slower compared to samples omitting 284 supplementation. (Figure 6). While previous findings suggest that flavins are not critical mediators 285 of electron transfer to soluble metal acceptors ${ }^{32,34}$, their function in precipitation of soluble $\mathrm{Pd}$ 286 appears more nuanced and with competing factors at play. Attenuated $\mathrm{Pd}(\mathrm{II})$ reduction could be 287 explained by flavins binding and sequestering soluble $\mathrm{Pd}(\mathrm{II})$. Flavins could also act as capping 288 agents that passivate growing nanoparticle surfaces and hinder further Pd(II) reduction ${ }^{37}$. Indeed, 289 the presence of riboflavin or flavin mononucleotide in an abiotic synthesis of Pd nanoparticles 290 using $\mathrm{NaBH}_{4}$ prevented significant particle aggregation relative to a flavin-free control (Figure 291 S20). Overall, our results demonstrate that flavin concentration exerts control over Pd 292 nanoparticle size and reduction rate without affecting their cellular localization.

\section{Implications}

295 To summarize, we determined that the EET components, MtrC and flavins, can exert 296 significant influence over Pd nanoparticle formation by Shewanella oneidensis. By adjusting their 297 concentration in the bacterial environment, significant changes were actuated in Pd nanoparticle 298 synthesis rate, size, and cellular localization.

299 Knockout and complementation experiments confirmed that the outer membrane cytochrome, $300 \mathrm{MtrC}$, is a critical enabler of rapid $\mathrm{Pd}(\mathrm{II})$ reduction and extracellular nanoparticle nucleation. 301 Notably, expression of MtrC via an engineered plasmid led to $\mathrm{Pd}(\mathrm{II})$ reduction rates that were 302 faster than wild-type controls. Given this observation, coupled with the loss of extracellular 303 particles on mtrC knockouts, we hypothesize that more fine-tuned expression of MtrC may 304 correlate to different numbers and sizes of produced nanoparticles. This strategy may also be 305 adapted to standard chassis organisms that express functional MtrC, such as engineered E. coli 306 strains $^{38}$, or other electroactive bacteria possessing $\mathrm{Pd}(\mathrm{II})$-reducing outer membrane cytochromes 
307 (e.g. Geobacter sulfurreducens) ${ }^{39,40}$. Alternatively, nanoparticle formation could be varied by 308 directly engineering the MtrC polypeptide sequence, either through rational or evolutionary 309 mutagenesis. Altering the redox-potential and catalytic activity of heme-containing proteins is well310 precedented ${ }^{41}$, and key mutations could be applied to identify/tune the $\mathrm{Pd}(\mathrm{II})$ reduction activity of 311 MtrC hemes ${ }^{42}$. Additionally, a binding-site for iron oxide nanoparticles to the outer membrane 312 cytochrome, MtrF, has recently been elucidated using protease footprinting ${ }^{43}$, and similar 313 methods could be used to identify and affect residues involved in particle nucleation by MtrC.

314 We observed a decrease in the size of $\mathrm{Pd}$ nanoparticles with increasing concentration of 315 supplemented flavins to nanoparticle reaction mixtures. Reduction kinetics again appear to play 316 a role in nanoparticles produced in the presence of flavins; however, unlike the effect of $m t r C$ 317 deletion, nanoparticles formed with flavins were extracellularly bound to the bacterial membrane. 318 Given our understanding of flavin interaction with soluble metals and metal surfaces, it is likely 319 that increased flavin concentration alters nanoparticle dimensions through binding and nucleation interactions. Shewanella-secreted flavins have been measured as $\sim 0.1-1.5 \mu \mathrm{M}$ in culture supernatants ${ }^{34,44}$, therefore our supplementations $(100 \mu \mathrm{M})$ far exceeded physiologically generated concentrations. However, strains with additional flavin biosynthesis pathways have increased secreted concentrations to as high as $\sim 25 \mu \mathrm{M}^{45}$. Further pathway engineering would likely increase this concentration and potentially allow for stimuli-responsive pathways to control nanoparticle size. Flavin binding to outer membrane cytochromes likely also plays a role in the observed particle phenotypes ${ }^{35}$, and we speculate that modulating flavin-cytochrome binding affinities through protein engineering could produce similar effects without exogenous supplementation $^{42}$. Overall, our results shed further light on the role of flavins in S. oneidensismetal chemistry and demonstrate another means of tunability for biological nanoparticle synthesis.

Biological generation of inorganic structures most commonly arises in nature through the actions of complex protein and metabolic networks. However, engineered systems have been described where relatively simple biological interactions (e.g. amyloid fibers ${ }^{3}$, phage scaffolds ${ }^{46}$ ) can direct nanomaterial morphologies. We present an alternative strategy that uses single genetic or metabolic factors of viable $\mathrm{S}$. oneidensis cells to control Pd nanoparticle phenotype. Our results, combined with the genetic tractability of $S$. oneidensis, suggest that it may serve as an intriguing model platform for studying nanoparticle biogenesis and engineering these particles for catalysis and sensing applications. 


\section{Materials and Methods}

341 Chemicals and Reagents

342 Sodium tetrachloropalladate(II) trihydrate $\left(\mathrm{Na}_{2} \mathrm{PdCl}_{4} \cdot 3 \mathrm{H}_{2} \mathrm{O}\right.$, Strem Chemicals), argon (Ar, Airgas),

343 4-(2-Pyridylazo)resorcinol $\left(\mathrm{C}_{11} \mathrm{H}_{9} \mathrm{~N}_{3} \mathrm{O}_{2}\right.$, Alfa Aesar), HEPES Free Acid Powder $\left(\mathrm{C}_{8} \mathrm{H}_{18} \mathrm{~N}_{2} \mathrm{O}_{4} \mathrm{~S}\right.$,

344 Sigma-Aldrich), potassium phosphate dibasic $\left(\mathrm{K}_{2} \mathrm{HPO}_{4}\right.$, Sigma-Aldrich), potassium phosphate 345 monobasic $\left(\mathrm{KH}_{2} \mathrm{PO}_{4}, \mathrm{VWR}\right)$, sodium chloride $(\mathrm{NaCl}, \mathrm{VWR})$, ammonium sulfate $\left(\mathrm{NH}_{4}\right)_{2} \mathrm{SO}_{4}$, Fisher 346 Scientific), magnesium(II) sulfate heptahydrate $\left(\mathrm{MgSO}_{4} \cdot 7 \mathrm{H}_{2} \mathrm{O}\right.$, Sigma-Aldrich), EDTA acid 347 disodium salt dihydrate $\left(\mathrm{C}_{10} \mathrm{H}_{14} \mathrm{~N}_{2} \mathrm{Na}_{2} \mathrm{O}_{8} \cdot 2 \mathrm{H}_{2} \mathrm{O}, \mathrm{VWR}\right)$, manganese(II) sulfate monohydrate $348\left(\mathrm{MnSO}_{4} \cdot \mathrm{H} 2 \mathrm{O}, \mathrm{VWR}\right)$, ferrous sulfate heptahydrate $\left(\mathrm{FeSO}_{4} \cdot 7 \mathrm{H}_{2} \mathrm{O}\right.$, Alfa Aesar), cobalt(II) nitrate 349 hexahydrate $\left(\mathrm{Co}\left(\mathrm{NO}_{3}\right)_{2} \cdot 6 \mathrm{H}_{2} \mathrm{O}\right.$, Strem Chemicals), calcium chloride dihydrate $\left(\mathrm{CaCl}_{2} \cdot 2 \mathrm{H}_{2} \mathrm{O}\right.$, 350 Sigma-Aldrich), zinc(II) sulfate monohydrate $\left(\mathrm{ZnSO}_{4} \cdot \mathrm{H}_{2} \mathrm{O}\right.$, Strem Chemicals), cupric sulfate 351 pentahydrate $\left(\mathrm{CuSO}_{4} \cdot 5 \mathrm{H}_{2} \mathrm{O}, \mathrm{VWR}\right)$, aluminum potassium sulfate $\left(\mathrm{AlK}\left(\mathrm{SO}_{4}\right)_{2}\right.$, Acros Organics), 352 boric acid $\left(\mathrm{H}_{3} \mathrm{BO}_{3}, V W R\right)$, sodium molybdate dihydrate $\left(\mathrm{Na}_{2} \mathrm{MoO}_{4} \cdot 2 \mathrm{H}_{2} \mathrm{O}\right.$, Beantown Chemical), 353 sodium selenite $\left(\mathrm{Na}_{2} \mathrm{SeO}_{3}\right.$, Acros Organics), sodium tungstate dihydrate $\left(\mathrm{Na}_{2} \mathrm{WO}_{4} \cdot 2 \mathrm{H}_{2} \mathrm{O}\right.$, Alfa 354 Aesar), nickel(II) chloride hexahydrate $\left(\mathrm{NiCl}_{2} \cdot 6 \mathrm{H}_{2} \mathrm{O}\right.$, Alfa Aesar), D-(+)-glucose $\left(\mathrm{C}_{6} \mathrm{H}_{12} \mathrm{O}_{6}\right.$, Sigma355 Aldrich), flavin adenine dinucleotide disodium salt hydrate $\left(\mathrm{C}_{27} \mathrm{H}_{31} \mathrm{~N}_{9} \mathrm{Na}_{2} \mathrm{O}_{15} \mathrm{P}_{2} \cdot x \mathrm{H}_{2} \mathrm{O}\right.$, Sigma356 Aldrich), riboflavin $\left(\mathrm{C}_{17} \mathrm{H}_{20} \mathrm{~N}_{4} \mathrm{O}_{6}\right.$, Alfa Aesar), kanamycin sulfate $\left(\mathrm{C}_{18} \mathrm{H}_{38} \mathrm{~N}_{4} \mathrm{O}_{15} \mathrm{~S}\right.$, Growcells) and 357 casamino acids (VWR) were used as received. For thin section preparation, cacodylate buffer, 358 glutaraldehyde (50\%), paraformaldehyde (16\%), potassium ferrocyanide, and osmium tetroxide, 359 and epoxy resin solutions were obtained from Electron Microscopy Sciences. Sodium DL-lactate $360\left(\mathrm{C}_{3} \mathrm{H}_{5} \mathrm{NaO}_{3}, V W R, 60 \%\right.$ in water $)$ was filtered using $0.2 \mu \mathrm{m}$ PES filters. Sodium fumarate $361\left(\mathrm{Na}_{2} \mathrm{C}_{4} \mathrm{H}_{2} \mathrm{O}_{4}, V W R\right)$ was diluted in $\mathrm{H}_{2} \mathrm{O}$ and then filtered using $0.2 \mu \mathrm{m}$ PES filters. LB Lennox agar 362 powder (VWR) was dissolved in $\mathrm{H}_{2} \mathrm{O}$ and sterilized at $121^{\circ} \mathrm{C}$ and $100 \mathrm{kPa}$ for $1 \mathrm{~h}$. Kanamycin 363 sulfate stock was dissolved in $\mathrm{H}_{2} \mathrm{O}$ and filter sterilized using $0.2 \mu \mathrm{m}$ PES filters. When preparing 364 Shewanella Basal Medium, all components were added to $\mathrm{H}_{2} \mathrm{O}$ and filter-sterilized using $0.2 \mu \mathrm{m}$ 365 PES filters.

Bacterial Strains and Culture

368 Bacterial strains, plasmids, and their sources are listed in Table S1. Except where noted, liquid cultures and nanoparticle biosynthesis reactions occurred in autoclaved Hungate culture tubes capped with a butyl-rubber stopper and plastic screw-cap. Pregrowth for nanoparticle

371 biosynthesis reactions was prepared as follows. Bacterial stocks stored in $20 \%$ glycerol at $-80{ }^{\circ} \mathrm{C}$ 372 were freshly streaked onto LB agar plates (containing $25 \mathrm{\mu g} \mathrm{mL}^{-1}$ kanamycin when appropriate) 
373 and incubated aerobically for $\sim 18$ hours at $30^{\circ} \mathrm{C}(S$. oneidensis $)$ or $37^{\circ} \mathrm{C}(E$. coli). Colonies were

374 picked from these plates and used to inoculate Hungate tubes containing pregrowth medium that

375 was comprised of Shewanella Basal Medium with $100 \mathrm{mM} \mathrm{HEPES}^{47}, 5 \mathrm{~mL} \mathrm{~L}^{-1}$ trace metal mix ${ }^{48}$,

$3760.5 \%$ casamino acids, $20 \mathrm{mM}$ sodium lactate (S. oneidensis) or $20 \mathrm{mM}$ glucose (E. coli), and 40

$377 \mathrm{mM}$ sodium fumarate. After inoculation, tubes were incubated at $30^{\circ} \mathrm{C}$ and shaken for $\sim 18$ hours

378 at $250 \mathrm{rpm}$. Anoxic conditions were maintained by bubbling all solutions, flushing tube headspace,

379 and overpressuring Hungate tubes (>15 psi) with argon. During transient exposure to atmosphere

380 (during inoculation and between washes/centrifugations), solutions were strictly handled under a

381 gassing cannula that jettisoned argon.

\section{Nanoparticle Biosynthesis}

384 To prepare $3 \mathrm{~mL}$ of a standard nanoparticle biosynthesis reaction, $4 \mathrm{~mL}$ of anaerobic pregrowth was started the previous day. Once pregrowth reached stationary-phase, the entire volume was transferred to a $15 \mathrm{~mL}$ conical tube and centrifuged at $3400 \mathrm{xg}$ for $1 \mathrm{~h}$. The supernatant was removed, $1 \mathrm{~mL}$ of degassed SBM containing trace metal mix was used to resuspend the pellet, and this suspension was subsequently transferred to a sterile $1.5 \mathrm{~mL}$ microcentrifuge tube for centrifugation at $6000 \mathrm{xg}$ for 20 minutes. A second $1 \mathrm{~mL}$ SBM wash/centrifugation was performed and the bacterial suspension was concentrated to an $\mathrm{OD}_{600}$ of 3.0 in $200 \mu \mathrm{L}$, which was to be later used as reaction inoculum. $2.8 \mathrm{~mL}$ of reaction volume was prepared by mixing $8.55 \mu \mathrm{L}$ of sodium lactate $(60 \% \mathrm{w} / \mathrm{w})$ and $30 \mu \mathrm{L}$ of freshly prepared $10 \mathrm{mM} \mathrm{Na} \mathrm{PdCl}_{4} \cdot 3 \mathrm{H}_{2} \mathrm{O}$ (dissolved in autoclaved Milli-Q $\mathrm{H}_{2} \mathrm{O}$ ) to $2.76 \mathrm{~mL}$ of SBM containing trace metals. This mixture was bubbled with argon and then transferred to sealed Hungate tubes. Prior to inoculation, tube headspace was flushed with additional argon for 15 minutes. Using sterile syringe needles, the entire bacterial inoculum volume was injected into to the reaction mixture, setting the final $\mathrm{OD}_{600}$ to 0.2 ., and the first time point was simultaneously aliquoted. The headspace of reaction mixtures was briefly flushed with argon for 1 minute, and incubated inside a shaker at $30^{\circ} \mathrm{C}$ and $250 \mathrm{rpm}$. All time point aliquots $(\sim 300 \mu \mathrm{L})$ were flash frozen in liquid $\mathrm{N}_{2}$ and store at $-20^{\circ} \mathrm{C}$ for later analysis. Reactions with higher concentrations of $\mathrm{Pd}(\mathrm{II})$ or $0.5 \%$ casamino acids were performed when indicated. For reactions inoculated with plasmid-complemented knockouts, kanamycin was supplemented to mixtures at a concentration of $25 \mu \mathrm{g} \mathrm{mL}^{-1}$. For $E$. coli-inoculated reactions, sodium lactate was replaced with $40320 \mathrm{mM}$ glucose and reactions were incubated at $37^{\circ} \mathrm{C}$. As noted in the Results and Discussion, 404 the age of HEPES in SBM pregrowth and reaction mixtures significantly affected Pd(II) reduction. 405 Therefore, HEPES was dissolved in SBM for pregrowth and nanoparticle reaction mixtures and 406 used within 2 weeks. 


\section{Transmission Electron Microscopy}

409 Palladized bacteria were prepared as described above. Nanoparticle synthesis was stopped after

4102 hours $(100 \mu \mathrm{M} \mathrm{Pd}(\mathrm{II}))$ or 24 hours $(1 \mathrm{mM} \mathrm{Pd}(\mathrm{II}))$, and cells were centrifuged/washed twice. In

411 early experiments, cells were washed with SBM containing trace metals as to minimize osmotic

412 shock, but we later found that autoclaved $\mathrm{H}_{2} \mathrm{O}$ could be utilized with minimal change in cell shape

413 and improved electron micrograph contrast. For whole mount TEM, washed cells were

414 concentrated to an $\mathrm{OD}_{600}$ of $\sim 2.7$ and $5 \mu \mathrm{L}$ was drop-cast onto glow-discharged 200 mesh carbon-

415 coated copper TEM grids (Electron Microscopy Sciences). For thin section TEM, cells were fixed

416 prior to sectioning and imaging. First, a $100 \mathrm{~mL}$ cation stock solution was prepared that contained

$417 \mathrm{CaCl}_{2} \cdot 2 \mathrm{H}_{2} \mathrm{O}(0.3 \mathrm{~g})$ and $\mathrm{MgSO}_{4} \cdot 7 \mathrm{H}_{2} \mathrm{O}(1 \mathrm{~g})$. Next, aldehyde fixation solution was prepared by 418 mixing $1 \mathrm{~mL}$ of cation stock with $5 \mathrm{~mL}$ of cacodylate buffer $(0.2 \mathrm{M}, \mathrm{pH} 7.4), 0.8 \mathrm{~mL}$ of 419 glutaraldehyde $(50 \%), 1.25 \mathrm{~mL}$ of paraformaldehyde $(16 \%)$, and $2 \mathrm{~mL}$ of $\mathrm{H}_{2} \mathrm{O}$. The washed cell 420 pellet was resuspended in $1 \mathrm{~mL}$ of aldehyde fixation solution and incubated at room temperature 421 for 4 hours. After, cells were washed three times in $0.1 \mathrm{M}$ cacodylate buffer. An osmium tetroxide 422 fixation solution was prepared immediately before use by mixing in a $1: 1$ ratio of $4 \%$ potassium 423 ferrocyanide in $0.2 \mathrm{M}$ cacodylate buffer (also prepared immediately before use) and $4 \%$ osmium 424 tetroxide. The cell pellet was resuspended in $1 \mathrm{~mL}$ osmium textroxide fixation solution and 425 incubated for 4 hours on ice. Next, the pellet was resuspended in $\mathrm{H}_{2} \mathrm{O}$ for 10 minutes, spun-down, 426 and repeated until the supernatant was clear ( 10 washes required). Subsequently, the pellet 427 was dehydrated in 50,70, 95\%, and 100\% (twice) ethanol, for 15 minutes at each dehydration. 428 After the final $100 \%$ ethanol wash, the pellet was washed in acetone for 15 minutes, twice. Next, 429 the pellet was infiltrated with $30 \%$ epoxy resin in $100 \%$ acetone, $66 \%$ resin in $100 \%$ acetone, and 430 finally $100 \%$ resin (twice), for $\sim 16$ hours with each infiltration. Finally, the pellet was placed in 431 fresh epoxy resin, cast into a sectioning-block mold, and heated at $65^{\circ} \mathrm{C}$ for 2 days. Sectioning 432 was accomplished using a Leica UltraCut Microtome and sections were placed on copper TEM 433 grids to for imaging. Whole mount and thin section TEM was performed using a FEI Tecnai 434 Transmission Electron Microscope.

436 Pd(II) Quantification

437 Extracellular $\mathrm{Pd}(\mathrm{II})$ concentrations were primarily quantified using the colorimetric 4-(2438 pyridylazo)-resorcinol (PAR) assay ${ }^{49}$, the general procedure is as follows. A $0.1 \%$ PAR stock 439 solution was freshly prepared by dissolving $25 \mathrm{mg} \mathrm{PAR}$ in $1 \mathrm{~mL} 1 \% \mathrm{NaOH}$, and then adding this 440 solution to $24 \mathrm{~mL}$ MilliQ $\mathrm{H}_{2} \mathrm{O}$. A stock solution of $100 \mathrm{mM}$ EDTA was also prepared and the $\mathrm{pH}$ 
441 was adjusted to 10.5 using $\mathrm{NaOH}$. Frozen nanoparticle reaction mixture aliquots $(\sim 300 \mu \mathrm{L})$ were

442 quickly thawed and centrifuged at 10,000xg for 5 minutes to pellet bacteria. Next, $100 \mu \mathrm{L}$ of each

443 reaction mixture supernatant was added to microcentrifuge tubes containing $500 \mu \mathrm{L}$ of the 100

$444 \mathrm{mM}$ EDTA stock and $5 \mu \mathrm{L}$ of the $0.1 \%$ PAR stock. This solution was heated at $80{ }^{\circ} \mathrm{C}$ for 10

445 minutes, cooled at $4{ }^{\circ} \mathrm{C}$ for 20 minutes, and absorbance at $515 \mathrm{~nm}$ was measured using a

446 CLARIOStar platereader (BMG Labtech). Standard curves were prepared in SBM containing

447 trace metals over a range of $0-125 \mu \mathrm{M} \mathrm{Pd}(\mathrm{II})$. Flavins exhibit absorbance overlapping that of PAR,

448 which obscured $\mathrm{Pd}(\mathrm{II})$ quantification using this method. Therefore, inductively coupled plasma

449 mass spectrometry (ICP-MS) was used to obtain reduction kinetics in the presence of flavins. To

450 prepare samples for ICP-MS, aliquots were thawed, centrifuged at 10,000xg for 5 minutes, and

451 the supernatant mixed in a 1:1 ratio with strong ( 70\%) nitric acid. Samples were further diluted

45280 -fold in weak ( 2\%) nitric acid to bring total dissolved solids to ppm levels and then analyzed

453 using an Agilent 7500ce ICP-MS. Pd(II) concentration at each time point was then calculated

454 based on the degree of sample dilution.

455

Powder X-Ray Diffraction

457 To analyze biogenic particles by PXRD, $10 \mathrm{~mL}$ of nanoparticle reaction mixtures using $1000 \mu \mathrm{M}$

$458 \mathrm{Pd}(\mathrm{II})$ were prepared and inoculated with MR-1, $\Delta m \operatorname{trC} \Delta \mathrm{omcA}$, or $\Delta h y d A \Delta h y a B$. After $\sim 18$ hours, 459 cells were washed by centrifuging at 3400xg for 40 minutes, removing supernatant, and adding 460 equal volume of autoclaved MilliQ $\mathrm{H}_{2} \mathrm{O}$. Two more washes were performed, and after the 461 supernatant was removed in the final wash, $1 \mathrm{~mL}$ of acetone was used to resuspend the pellet.

462 This acetone-cell suspension was transferred to a microcentrifuge tube and centrifuged for 20 463 minutes at $6000 \mathrm{xg}$. Acetone was again used to resuspend cells, and this suspension was 464 vacufuged to aspirate the supernatant and pellet dried cell mass. X-ray diffraction (XRD) was 465 performed on a Rigaku R-Axis Spider diffractometer with an image plate detector using $\mathrm{Cu} \mathrm{Ka}$ 466 radiation $(\lambda=1.54 \AA)$ and a graphite monochromator. XRD samples were prepared by mixing a 467 small amount of dried cell mass with a droplet of mineral oil followed by mounting on a cryoloop.

Statistical Analysis

470 Unless otherwise noted, data are reported as mean \pm S.E. of $n=3$ replicates, as this sample size 471 was sufficiently large to detect significant differences in means. Significance was calculated using 472 a two-tailed unpaired Student's t-test $(\alpha=0.05)$ and OriginPro Software (OriginLab, Northhampton, $473 \mathrm{MA})$. 


\section{Author Contributions}

C.M.D. and B.K.K. conceived the project; C.M.D. and A.J.G. performed the experiments. D.K.R. assisted with electron microscopy preparation and experiments. C.M.D., A.J.G., and B.K.K. analyzed the results. C.M.D., A.J.G., and B.K.K. wrote the manuscript.

\section{Acknowledgements}

481 This work was supported by the Welch Foundation (Grant No. F-1929). We would like to thank 482 Prof. Jeffrey Gralnick (U. Minnesota) for generously providing S. oneidensis strains $\Delta m \operatorname{tr} \triangle \Delta \mathrm{mcA}$ 483 and $\triangle h y d A \Delta h y a B$ and Prof. Lydia Contreras (U. Texas at Austin) for generously providing E. coli 484 MG1655. We would like to acknowledge ICMB Core Facilities at the UT Austin for use of their 485 Tecnai Transmission Electron Microscope and performing DNA sequencing. We also 486 acknowledge Dr. Nathaniel R. Miller and the Jackson School of Geosciences at UT Austin for support with ICP-MS experiments.

\section{Notes}

490 The authors declare no competing financial interests.

\section{References}

493 (1) Ajikumar, P. K., Xiao, W. H., Tyo, K. E. J., Wang, Y., Simeon, F., Leonard, E., Mucha, O., 494 Phon, T. H., Pfeifer, B., and Stephanopoulos, G. (2010) Isoprenoid Pathway Optimization for 495 Taxol Precursor Overproduction in Escherichia coli. Science 330, 70-74.

496 (2) Keasling, J. D. (2010) Manufacturing Molecules Through Metabolic Engineering. Science 330, 497 1355-1358.

498 (3) Chen, A. Y., Deng, Z., Billings, A. N., Seker, U. O. S., Lu, M. Y., Citorik, R. J., Zakeri, B., and 499 Lu, T. K. (2014) Synthesis and patterning of tunable multiscale materials with engineered cells. 500 Nature Materials 13, 515-523.

501 (4) Lovley, D. R. (2017) e-Biologics: Fabrication of Sustainable Electronics with "Green" Biological 502 Materials. mBio (Sperandio, V., Ed.) 8, e00695-17-7.

503 (5) Edmundson, M. C., Capeness, M., and Horsfall, L. (2014) Exploring the potential of metallic 504 nanoparticles within synthetic biology. New Biotechnology 31, 572.

505 (6) Hildebrand, M. (2008) Diatoms, Biomineralization Processes, and Genomics. Chem. Rev. 108, 506 4855-4874.

507 (7) Faivre, D., and Godec, T. U. (2015) From Bacteria to Mollusks: The Principles Underlying the 508 Biomineralization of Iron Oxide Materials. Angew. Chem. 127, 4810-4829. 
(8) Uebe, R., and Schüler, D. (2016) Magnetosome biogenesis in magnetotactic bacteria. Nature Reviews Microbiology 14, 621-637.

511 (9) Shi, L., Dong, H., Reguera, G., Beyenal, H., Lu, A., Liu, J., Yu, H.-Q., and Fredrickson, J. K. 512 (2016) Extracellular electron transfer mechanisms between microorganisms and minerals. Nature 513 Reviews Microbiology 14, 651-662.

514 (10) Fredrickson, J. K., Romine, M. F., Beliaev, A. S., Auchtung, J. M., Driscoll, M. E., Gardner, 515 T. S., Nealson, K. H., Osterman, A. L., Pinchuk, G., Reed, J. L., Rodionov, D. A., Rodrigues, J. L. 516 M., Saffarini, D. A., Serres, M. H., Spormann, A. M., Zhulin, I. B., and Tiedje, J. M. (2008) Towards 517 environmental systems biology of Shewanella. Nature Reviews Microbiology 6, 592-603.

518 (11) Coursolle, D., and Gralnick, J. A. (2012) Reconstruction of extracellular respiratory pathways 519 for iron(III) reduction in Shewanella oneidensis strain MR-1. Frontiers in Microbiology 3, 1-11. (12) Coursolle, D., and Gralnick, J. A. (2010) Modularity of the Mtr respiratory pathway of Shewanella oneidensis strain MR-1. Molecular Microbiology 55, 995-1008. (13) Coursolle, D., Baron, D. B., Bond, D. R., and Gralnick, J. A. (2010) The Mtr Respiratory Pathway Is Essential for Reducing Flavins and Electrodes in Shewanella oneidensis. Journal of Bacteriology 192, 467-474. Boyanov, M. I., Lai, B., Kemner, K. M., McLean, J. S., Reed, S. B., Culley, D. E., Bailey, V. L., Simonson, C. J., Saffarini, D. A., Romine, M. F., Zachara, J. M., and Fredrickson, J. K. (2006) C -Type Cytochrome-Dependent Formation of U(IV) Nanoparticles by Shewanella oneidensis. PLOS Biol (Ward, N., Ed.) 4, e268.

530 (15) Ng, C. K., Cai Tan, T. K., Song, H., and Cao, B. (2013) Reductive formation of palladium nanoparticles by Shewanella oneidensis: role of outer membrane cytochromes and 532 hydrogenases. RSC Adv. 3, 22498-6.

533 (16) Kimber, R. L., Lewis, E. A., Parmeggiani, F., Smith, K., Bagshaw, H., Starborg, T., Joshi, N., 534 Figueroa, A. I., van der Laan, G., Cibin, G., Gianolio, D., Haigh, S. J., Pattrick, R. A. D., Turner, 535 N. J., and Lloyd, J. R. (2018) Biosynthesis and Characterization of Copper Nanoparticles Using 536 Shewanella oneidensis: Application for Click Chemistry. Small 116, 1703145-8.

537 (17) Li, D.-B., Cheng, Y.-Y., Wu, C., Li, W.-W., Li, N., Yang, Z.-C., Tong, Z.-H., and Yu, H.-Q. 538 (2014) Selenite reduction by Shewanella oneidensis MR-1 is mediated by fumarate reductase in 539 periplasm. Scientific Reports 4.

540 (18) Tian, L.-J., Li, W.-W., Zhu, T.-T., Chen, J.-J., Wang, W.-K., An, P.-F., Zhang, L., Dong, J.-C., 541 Guan, Y., Liu, D.-F., Zhou, N.-Q., Liu, G., Tian, Y.-C., and Yu, H.-Q. (2017) Directed Biofabrication 542 of Nanoparticles through Regulating Extracellular Electron Transfer. Journal of the American 
544 (19) Marsili, E., Baron, D., Shikhare, I. D., Coursolle, D., Gralnick, J. A., and Bond, D. R. (2008)

545 Shewanella secretes flavins that mediate extracellular electron transfer. Proceedings of the 546 National Academy of Sciences 105, 3968-3973.

547 (20) De Windt, W., Aelterman, P., and Verstraete, W. (2005) Bioreductive deposition of palladium 548 (0) nanoparticles on Shewanella oneidensis with catalytic activity towards reductive 549 dechlorination of polychlorinated biphenyls. Environmental Microbiology.

550 (21) De Windt, W., Boon, N., Van den Bulcke, J., Rubberecht, L., Prata, F., Mast, J., Hennebel, 551 T., and Verstraete, W. (2006) Biological control of the size and reactivity of catalytic $\operatorname{Pd}(0)$ 552 produced by Shewanella oneidensis. Antonie van Leeuwenhoek 90, 377-389.

553 (22) Cheng, H.-Y., Hou, Y.-N., Zhang, X., Yang, Z.-N., Xu, T., and Wang, A.-J. (2017) Activating 554 electrochemical catalytic activity of bio-palladium by hybridizing with carbon nanotube as "e555 Bridge." Scientific Reports 1-9.

556 (23) Jin, M., Zhang, H., Xie, Z., and Xia, Y. (2012) Palladium nanocrystals enclosed by $\{100\}$ and

$557\{111\}$ facets in controlled proportions and their catalytic activities for formic acid oxidation. Energy

558 Environ. Sci. 5, 6352-6357.

559 (24) Coppage, R., Slocik, J. M., Briggs, B. D., Frenkel, A. I., Naik, R. R., and Knecht, M. R. (2012) 560 Determining peptide sequence effects that control the size, structure, and function of 561 nanoparticles. ACS Nano 6, 1625-1636.

562 (25) Zhou, C., Ontiveros-Valencia, A., Wang, Z., Maldonado, J., Zhao, H.-P., Krajmalnik-Brown,

563 R., and Rittmann, B. E. (2016) Palladium Recovery in a H 2-Based Membrane Biofilm Reactor:

564 Formation of $\mathrm{Pd}(0)$ Nanoparticles through Enzymatic and Autocatalytic Reductions.

565 Environmental Science \& Technology 50, 2546-2555.

566 (26) Mikheenko, I. P., Rousset, M., Dementin, S., and Macaskie, L. E. (2008) Bioaccumulation of 567 Palladium by Desulfovibrio fructosivorans Wild-Type and Hydrogenase-Deficient Strains. Applied 568 and Environmental Microbiology 74, 6144-6146.

569 (27) Deplanche, K., Caldelari, I., Mikheenko, I. P., Sargent, F., and Macaskie, L. E. (2010) 570 Involvement of hydrogenases in the formation of highly catalytic $\operatorname{Pd}(0)$ nanoparticles by 571 bioreduction of $\mathrm{Pd}(\mathrm{II})$ using Escherichia coli mutant strains. Microbiology 156, 2630-2640.

572 (28) Klug, H. P., and Alexander, L. E. (1974) X-ray diffraction procedures: for polycrystalline and 573 amorphous materials. X-Ray Diffraction Procedures: For Polycrystalline and Amorphous 574 Materials, 2nd Edition, by Harold P. Klug, Leroy E. Alexander, pp. 992. ISBN 0-471-49369-4. 575 Wiley-VCH, May 1974. 992.

576 (29) Yin, Y., and Alivisatos, A. P. (2005) Colloidal nanocrystal synthesis and the organic-inorganic 
interface. Nature 437, 664-670.

578 (30) Kane, A. L., Brutinel, E. D., Joo, H., Maysonet, R., VanDrisse, C. M., Kotloski, N. J., and

579 Gralnick, J. A. (2016) Formate Metabolism in Shewanella oneidensis Generates Proton Motive

580 Force and Prevents Growth without an Electron Acceptor. Journal of Bacteriology (Silhavy, T. J.,

581 Ed.) $198,1337-1346$.

582 (31) Leaphart, A. B., Thompson, D. K., Huang, K., Alm, E., Wan, X. F., Arkin, A., Brown, S. D.,

583 Wu, L., Yan, T., Liu, X., Wickham, G. S., and Zhou, J. (2006) Transcriptome Profiling of

584 Shewanella oneidensis Gene Expression following Exposure to Acidic and Alkaline pH. Journal

585 of Bacteriology 188, 1633-1642.

586 (32) Fan, G., Dundas, C. M., Graham, A. J., Lynd, N. A., and Keitz, B. K. (2018) Shewanella 587 oneidensis as a living electrode for controlled radical polymerization. Proceedings of the National 588 Academy of Sciences 4, 201800869-6.

589 (33) Glasser, N. R., Saunders, S. H., and Newman, D. K. (2017) The Colorful World of 590 Extracellular Electron Shuttles. Annu. Rev. Microbiol. 71, annurev-micro-090816-093913-21.

591 (34) Kotloski, N. J., and Gralnick, J. A. (2013) Flavin Electron Shuttles Dominate Extracellular 592 Electron Transfer by Shewanella oneidensis. mBio 4, 1-4.

593 (35) Okamoto, A., Hashimoto, K., Nealson, K. H., and Nakamura, R. (2013) Rate enhancement 594 of bacterial extracellular electron transport involves bound flavin semiquinones. Proceedings of 595 the National Academy of Sciences 110, 7856-7861.

596 (36) Albert, A. (1950) The Metal-Binding Properties of Riboflavin. Biochem. J. 47, xxvii.

597 (37) Nadagouda, M. N., and Varma, R. S. (2006) Green and controlled synthesis of gold and 598 platinum nanomaterials using vitamin B2: density-assisted self-assembly of nanospheres, wires 599 and rods. Green Chem. 8, 516-3.

600 (38) Jensen, H. M., Albers, A. E., Malley, K. R., Londer, Y. Y., Cohen, B. E., Helms, B. A., Weigele, 601 P., Groves, J. T., and Ajo-Franklin, C. M. (2010) Engineering of a synthetic electron conduit in 602 living cells. Proceedings of the National Academy of Sciences 107, 19213-19218.

603 (39) Tuo, Y., Liu, G., Zhou, J., Wang, A., Wang, J., Jin, R., and Lv, H. (2013) Microbial formation 604 of palladium nanoparticles by Geobacter sulfurreducens for chromate reduction. Bioresource 605 Technology 133, 606-611.

606 (40) Yates, M. D., Cusick, R. D., and Logan, B. E. (2013) Extracellular Palladium Nanoparticle 607 Production using Geobacter sulfurreducens. ACS Sustainable Chemistry \& Engineering 1, 11656081171.

609 (41) Hyster, T. K., and Ward, T. R. (2016) Genetic Optimization of Metalloenzymes: Enhancing 610 Enzymes for Non-Natural Reactions. Angew. Chem. 128, 7468-7482. 
611 (42) Edwards, M. J., White, G. F., Norman, M., Tome-Fernandez, A., Ainsworth, E., Shi, L.,

612 Fredrickson, J. K., Zachara, J. M., Butt, J. N., Richardson, D. J., and Clarke, T. A. (2015) Redox

613 Linked Flavin Sites in Extracellular Decaheme Proteins Involved in Microbe-Mineral Electron

614 Transfer. Nature Publishing Group 1-11.

615 (43) Fukushima, T., Gupta, S., Rad, B., Cornejo, J. A., Petzold, C. J., Chan, L. J. G., Mizrahi, R.

616 A., Ralston, C. Y., and Ajo-Franklin, C. M. (2017) The Molecular Basis for Binding of an Electron

617 Transfer Protein to a Metal Oxide Surface. Journal of the American Chemical Society 139, 12647-

61812654.

619 (44) Covington, E. D., Gelbmann, C. B., Kotloski, N. J., and Gralnick, J. A. (2010) An essential 620 role for UshA in processing of extracellular flavin electron shuttles by Shewanella oneidensis.

621 Molecular Microbiology 78, 519-532.

622 (45) Yang, Y., Ding, Y., Bin Cao, Hu, Y., Bin Cao, Rice, S. A., Kjelleberg, S., and Song, H. (2015)

623 Enhancing Bidirectional Electron Transfer of Shewanella oneidensis by a Synthetic Flavin 624 Pathway. ACS Synthetic Biology 4, 815-823.

625 (46) Lee, S.-W., Mao, C., Flynn, C. E., and Belcher, A. M. (2002) Ordering of Quantum Dots Using 626 Genetically Engineered Viruses. Science 292, 892-895.

627 (47) Hau, H. H., Gilbert, A., Coursolle, D., and Gralnick, J. A. (2008) Mechanism and 628 Consequences of Anaerobic Respiration of Cobalt by Shewanella oneidensis Strain MR-1. 629 Applied and Environmental Microbiology 74, 6880-6886.

630 (48) Kane, A. L., Bond, D. R., and Gralnick, J. A. (2013) Electrochemical Analysis of Shewanella 631 oneidensis Engineered To Bind Gold Electrodes 2, 93.

632 (49) Rotaru, A.-E., Jiang, W., Finster, K., Skrydstrup, T., and Meyer, R. L. (2012) Non-Enzymatic 633 Palladium Recovery on Microbial and Synthetic Surfaces. Biotechnol. Bioeng. 109, 1889-1897. 
a
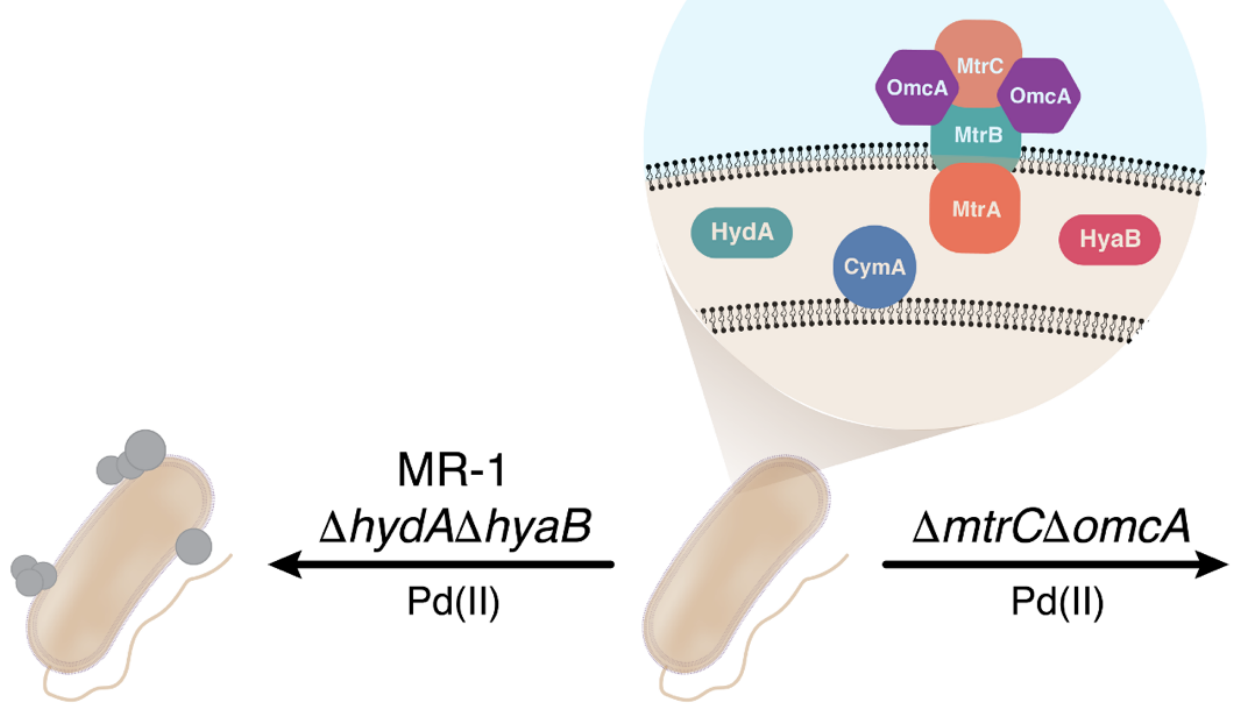

MR-1

$\Delta m \operatorname{trC} \Delta$ omcA $\Delta$ hydA $\Delta$ hyaB
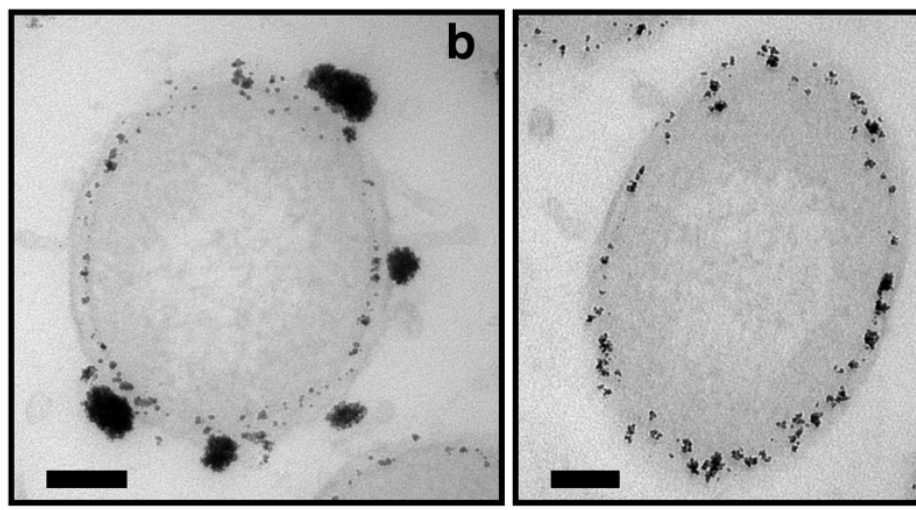

c
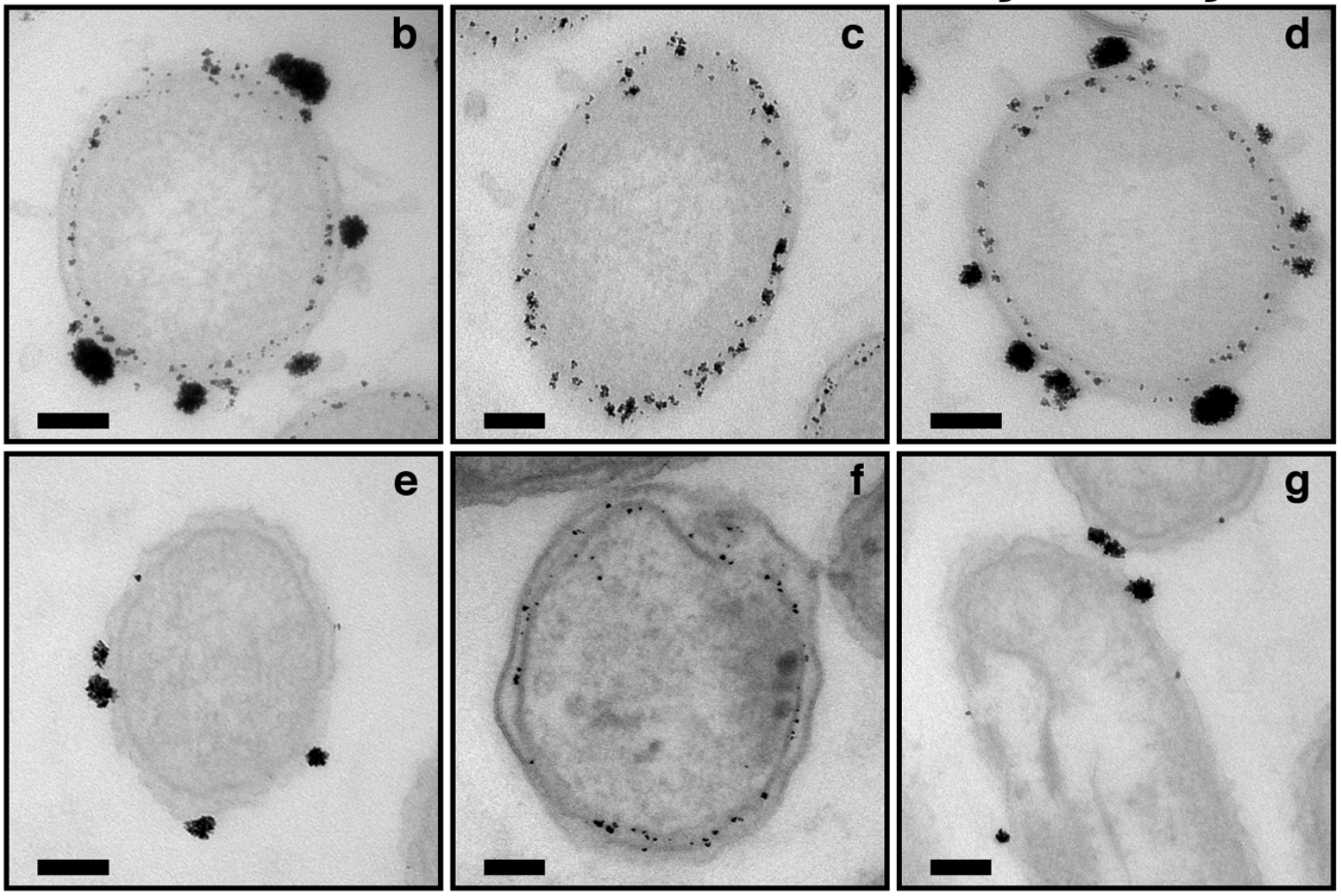

g
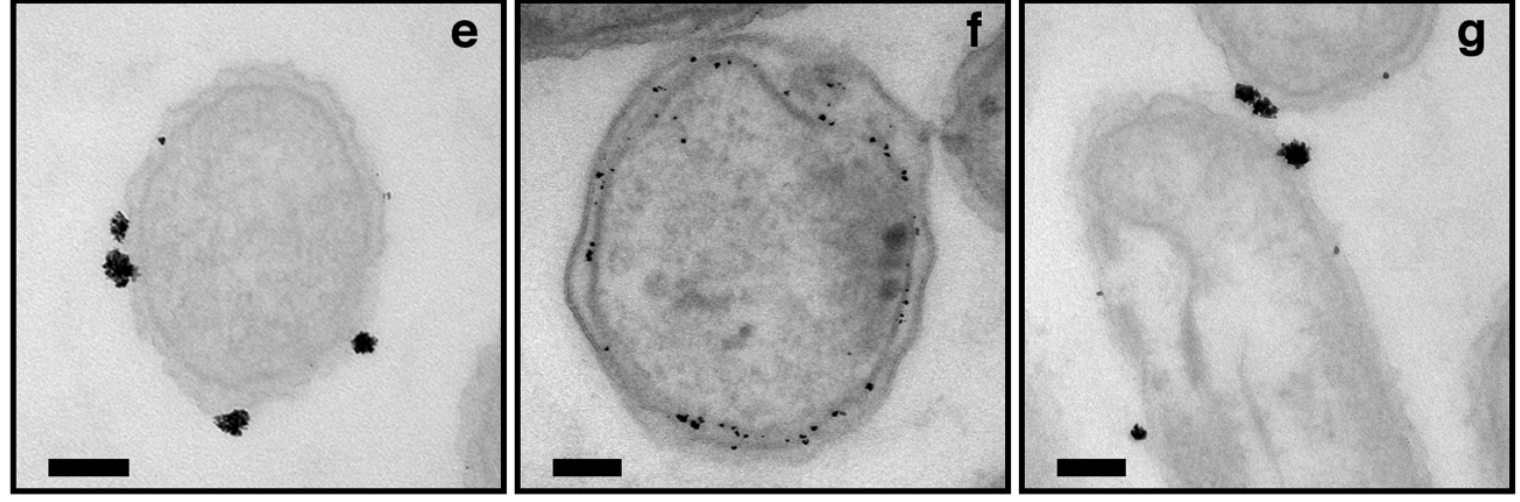

Figure 1. Formation of extracellular Pd nanoparticles requires outer membrane cytochromes. (a) General diagram of electron transport in S. oneidensis and genotypic effects on Pd nanoparticle formation. Thin section transmission electron micrographs of (b) MR-1, (c) $\triangle m \operatorname{tr} C \triangle O m c A$, and (d) $\Delta h y d A \Delta h y a B$ after 24 hour reactions containing $1000 \mu \mathrm{M} \mathrm{Pd}(\mathrm{II})$. (e) MR-1, (f) $\Delta m t r C \Delta o m c A$, and 


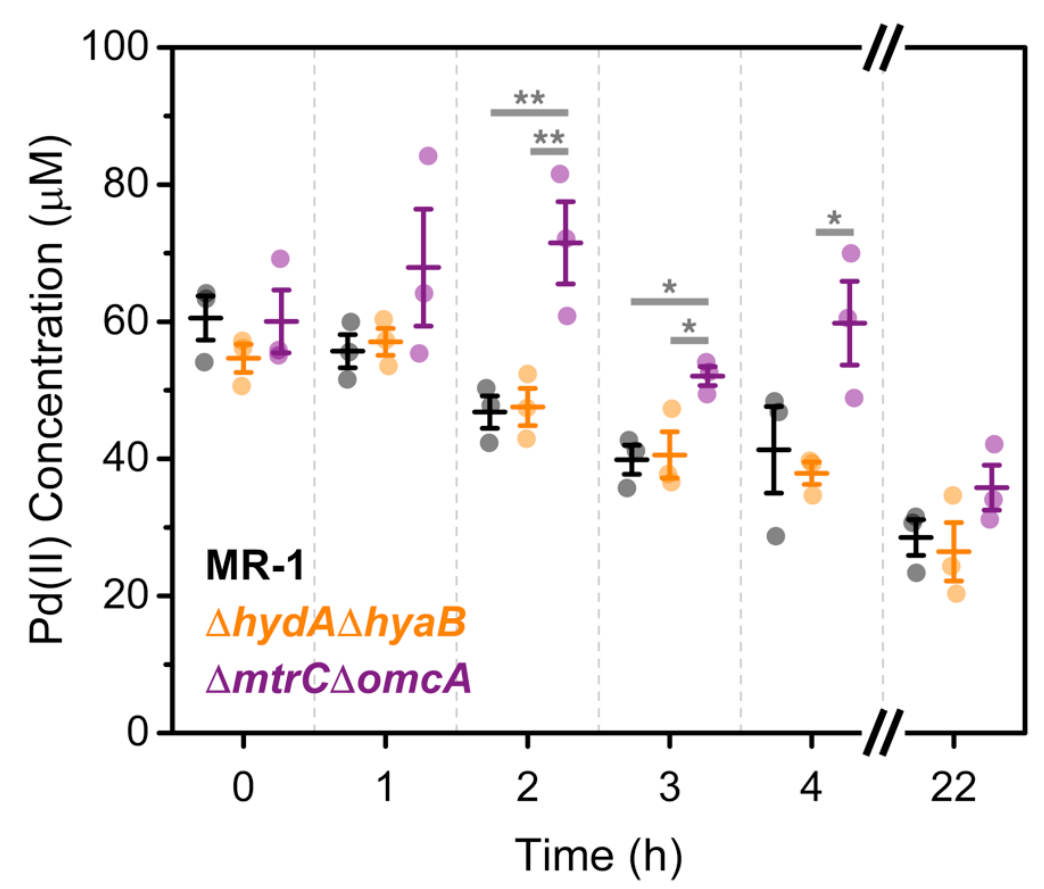

Figure 2. Loss of outer membrane cytochromes attenuates $\mathrm{Pd}(\mathrm{II})$ reduction rate. Extracellular

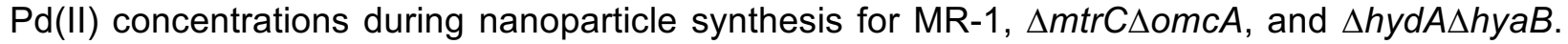
Raw data is overlaid on bars representing the mean \pm S.E. ${ }^{*} p<0.05,{ }^{* *} p<0.01, n=3$.

658

659

660

661

662

663

664

665

666

667

668

669

670 
671 


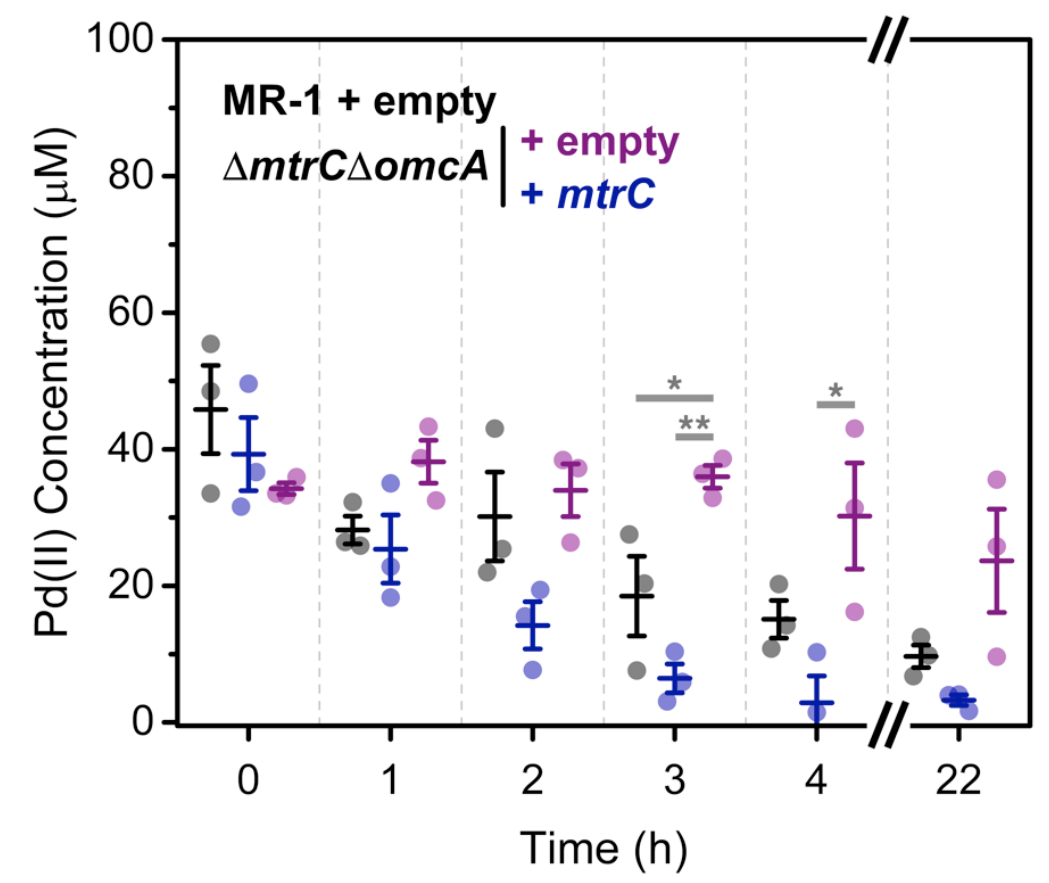

Figure 4. MtrC expression rescues $\mathrm{Pd}(\mathrm{II})$ reduction rate. Extracellular $\mathrm{Pd}(\mathrm{II})$ concentrations during nanoparticle synthesis for plasmid-complemented $S$. oneidensis strains. Raw data is overlaid on bars representing the mean \pm S.E. ${ }^{*} p<0.05,{ }^{* *} p<0.01, n=3$. 


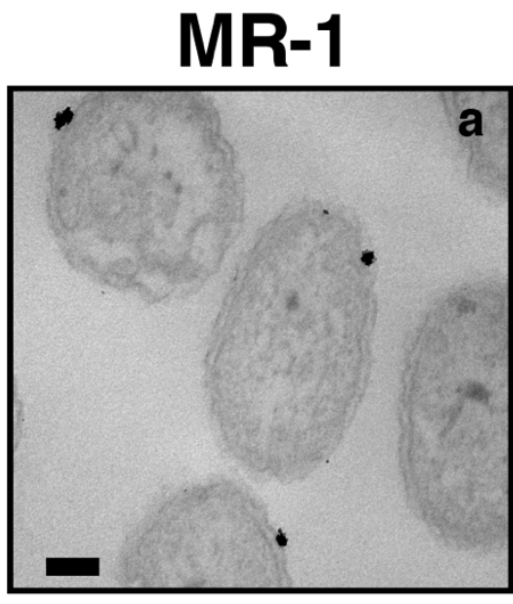

+RF

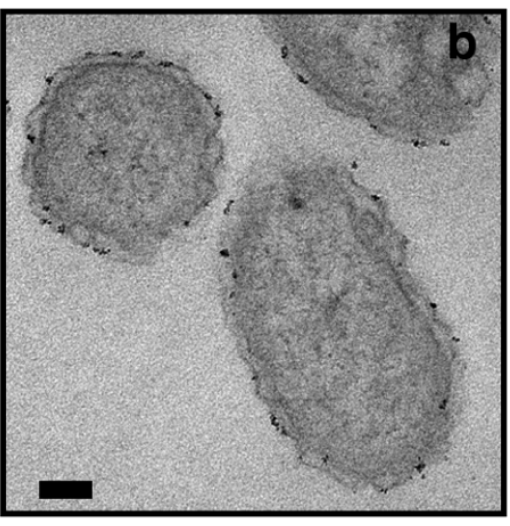

$+\mathrm{FMN}$

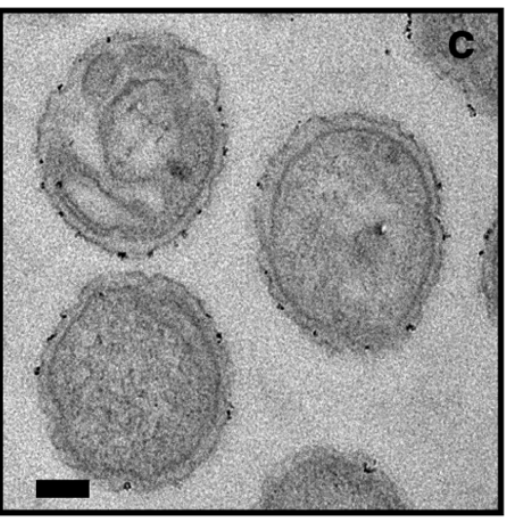

Figure 5. Flavin supplementation decreases size of extracellular Pd nanoparticles. Thin section transmission electron micrographs of (a) MR-1 and MR-1 with (b) $100 \mu \mathrm{M}$ riboflavin (RF) or (c) $100 \mu \mathrm{M}$ flavin mononucleotide (FMN) after 2 hours with $100 \mu \mathrm{M}$ Pd(II). Scale bars represent 100 $\mathrm{nm}$. 


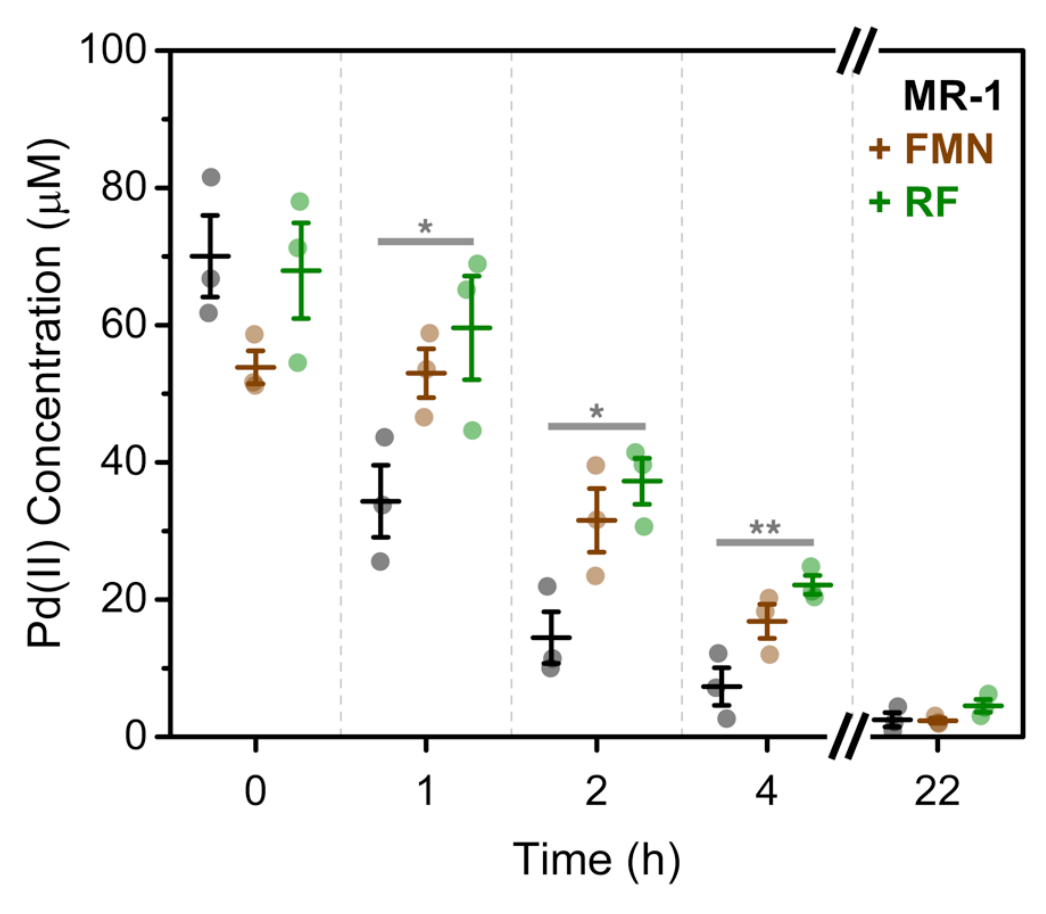

Figure 6. Flavin supplementation attenuates $\mathrm{Pd}(\mathrm{II})$ reduction rate by $\mathrm{S}$. oneidensis. Extracellular $\mathrm{Pd}$ (II) concentration for unsupplemented MR-1 and MR-1 supplemented with $100 \mu \mathrm{M}$ riboflavin (RF) or $100 \mu \mathrm{M}$ flavin mononucleotide (FMN). Raw data is overlaid on bars representing the mean \pm S.E. ${ }^{*} p<0.05,{ }^{* *} p<0.01, n=3$. 